TAPROBANICA, ISSN 1800-427X. November, 2020. Vol. 09, No. 02: pp. 194-204, pl. 53-54.

(C) Research Center for Climate Change and Department of Biology, Faculty of Mathematics \& Natural Sciences, University of Indonesia, Depok 16424, INDONESIA.

http://www.taprobanica.org/

https://doi.org/10.47605/tapro.v9i2.231

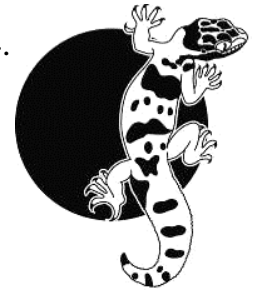

\title{
ON THE IDENTITY OF TWO Fejervarya FROG (DICROGLOSSIDAE) SPECIES FROM THE ANDAMAN AND NICOBAR ARCHIPELAGO
}

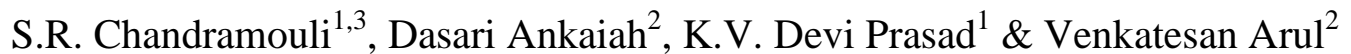 \\ ${ }^{1}$ Department of Ecology and Environmental Sciences, School of Life Sciences, Pondicherry University, \\ Puducherry 605014, India \\ ${ }^{2}$ Department of Biotechnology, School of Life Sciences, Pondicherry University, Puducherry 605014, India \\ ${ }^{3}$ Corresponding author. E-mail: findthesnakeman@gmail.com
}

\begin{abstract}
The taxonomic status of the large-sized Fejervarya frogs of the Andaman and Nicobar Islands was assessed based on integrative analysis of molecular, morphological and acoustic data. Our results identify the population from the Andaman Islands as Fejervarya moodiei, and that from the Nicobar Islands as $F$. limnocharis. Representative specimens collected during this study are described along with observations on their natural history. The distribution of $F$. moodiei within the Andaman Islands and $F$. limnocharis in the Nicobar Islands recorded during this study are mapped, suggesting that these species are fairly widespread.
\end{abstract}

Keywords: Fejervarya cancrivora, Fejervarya moodiei, Fejervarya limnocharis, India, mangrove

\section{Introduction}

The taxonomy of the frog genus Fejervarya Bolkay, 1915 has been of particular interest during the past decade and a number of studies have led to the discovery of several new species (e.g. Köhler et al. 2019) and taxonomic rearrangements (Dubois et al. 2001, Kuramoto et al. 2007, Sanchez et al. 2018). One group that has recently undergone such revision is the mangrove frogs of the Fejervarya cancrivora complex. Once considered to be widely distributed (Boulenger 1920, Dutta 1997), now several lineages with restricted geographic distributions have been identified (Islam et al. 2008, Kurniawan et al. 2010, Kurniawan et al. 2011). However, the status of certain populations that lie within the distribution range of this species complex could not be assessed owing to the lack of data. Such is the case with the Andaman population of this complex. The occurrence of Fejervarya cf. cancrivora in the Andaman Islands has been known since the report from South Andaman by Sarkar (1990) and Pillai (1991). Das (1999) regarded the identity of these frogs to be based on a species of the "Limnonectes limnocharis (Boie, 1835) complex". However, Fejervarya cf. cancrivora has recently been reported from the Andaman Islands by a few authors (e.g. Harikrishnan et al. 2012, Chandramouli et al. 2015). Until now, the precise systematic status of this population remained un-assessed (Frost 2020). Likewise, 
dicroglossid frogs of the genus Fejervarya have been assumed to comprise only two species in the Nicobar Islands, namely Fejervarya nicobariensis (Stoliczka, 1870) (=Minervarya nicobariensis according to Sanchez et al. 2018) and Fejervarya cancrivora (Gravenhorst, 1829) according to Das (1999). Vijayakumar (2005) reported the presence of a potentially new species of Fejervarya from the Nicobar Islands. However, no subsequent attempts have been made towards attaining a taxonomic resolution of this population. Recent surveys for amphibians conducted by us in the Andaman and Nicobar Islands recorded the presence of these large-bodied Fejervarya species from these islands, whose systematic affinities are assessed and clarified in this paper.

\section{Material and Methods}

Field sampling, collection and morphometry: Field surveys were conducted in Islands of the Andaman and Nicobar Archipelago to document its Anuran fauna between 2015 and 2017. Members of the large-bodied, mangrove dwelling Fejervarya cf. cancrivora from the Andaman Islands and the Fejervarya sp. recorded in the Nicobar Islands recorded during the study were captured by hand, gently restrained to score morphological characters and measured with a vernier caliper. The following measurements were recorded from each individual: snout-vent length (SVL, from the tip of the snout to the anterior margin of the cloaca), head length (HL, from the posterior edge of the mandible to the tip of the snout), head width (HW, the maximum width of the head at the angle of the jaws), head depth (HD, the maximum depth of the head), eye diameter (ED, the greatest horizontal diameter of the orbit), eye-nostril distance (EN, from the anterior border of the orbit to the middle of the nostril), eye-snout distance (ES, from the anterior border of the orbit to the tip of the snout), eyetympanum length (ETY, from the posterior border of the orbit to the anterior border of the tympanum), upper eyelid width (UEW, the maximum width of the upper eyelid), interorbital distance (IO, distance between the upper eyelids), internarial distance (IN, distance between the nostrils), tympanum diameter (TYD, the greatest horizontal diameter of the tympanum), upper arm length (UAL, from the axilla to elbow), lower arm length (LAL, from the posterior margin of the elbow to the base of the outer metacarpal tubercle), palm length
(PAL, from the posterior border of the outer metacarpal tubercle to tip of the $3^{\text {rd }}$ finger), femur length (FEL, from the cloaca to the knee), tibia length (TBL, from knee to heel), foot length (FOL, from inner metatarsal tubercle to the tip of the $4^{\text {th }}$ toe). Webbing formulae follow Savage \& Heyer (1997). Colour descriptions made here are based on our photographs of the species recorded during this study. Calls were recorded in the natural habitat using the digital audio recorder application in a Samsung Galaxy G130E model mobile phone and analyzed using the software packages Adobe: Soundbooth CS3 and Audition 1.0. Geographic coordinates of the localities of observation of this species were mapped using a GPS (WGS84 datum). One dead specimen (DOSMB 05031) of the mangrove dwelling Fejervarya species from Govind Nagar in Havelock Island, Ritchie's Archipelago of the Andaman group, and three specimens of the Fejervarya sp. from Camorta Island in the Nicobars were collected, preserved as vouchers and deposited at the Department of Ocean studies and Marine Biology, Pondicherry University, Port Blair (DOSMB) and the Zoological Survey of India, Andaman and Nicobar Regional Centre, Port Blair (ZSI ANRC). Three tadpoles of the Nicobar Fejervarya that were collected from dried up roadside puddles in Camorta Island and preserved in $70 \%$ ethanol were deposited in the collections as DOSMB05111. The following measurements of tadpoles were recorded: HBL, head-body length; HBW, head-body width; HBD, head-body depth; ODW, oral disc width; IO, inter-orbital distance; IN, inter-narial distance; $\mathrm{CFH}$ caudal-fin height; and $\mathrm{CMH}$, caudal muscle height, following Chandramouli \& Kalaimani (2014). Larvae were examined under a stereomicroscope for examination of characters and for measurements. Staging of tadpoles follow Gosner (1969) and terminologies follow McDiarmid \& Altig (1999). The oral apparatus of one of the tadpoles of the Nicobar Fejervarya sp. was dissected and studied under a Hitachi S3400N scanning electron microscope. The sample was kept in absolute ethanol overnight for desiccation. It was then dried completely and mounted on a metallic stub with a thin layer of adhesive. The mounted sample was then desiccated completely and coated with a thin film of gold. The gold coated sample was then subjected to exposure at different levels and under different degrees of magnification in the scanning electron 
microscope to study the detailed ultrastructure of the oral apparatus.

DNA extraction, amplification, sequencing and phylogenetic analysis: Total genomic DNA was extracted from liver tissues of one specimen of each species (DOSMB 05031 and ZSI/ANRC /T/12327) using a Himedia MB506 mammalian DNA extraction kit, following the manufacturer's protocols. 16s rRNA gene was amplified using the primers 16sAR-L (5'-CGCCTGTTTATCAA AAACAT-3') and 16sB R-H (5'-CCGGTCTGA ACTCAGATCACGT 3') respectively (Kocher et al. 1989). Amplifications were performed in a Biorad T100 thermal cycler: $50 \mu$ reactions with $25 \mu 1$ of P4600 Sigma-Aldrich ${ }^{\circledR}$ master mix, $2 \mu 1$ each of forward and reverse primers, $2 \mu 1$ of DNA template and $19 \mu \mathrm{l}$ of Milli-Q water with the following procedure: initial denaturation of DNA at $95{ }^{\circ} \mathrm{C}$ for $5 \mathrm{~min}, 35$ cycles of: denaturation at $95{ }^{\circ} \mathrm{C}$ for $1 \mathrm{~m}$, annealing at 55 ${ }^{\circ} \mathrm{C}$ for $1 \mathrm{~min}$, extension at $72{ }^{\circ} \mathrm{C}$ for $1 \mathrm{~m}$ and at last, final extension at $72{ }^{\circ} \mathrm{C}$ for $10 \mathrm{~min}$. The amplicon was checked by running it through an agarose gel electrophoresis for a clear band of the desired region in the amplified PCR product. The amplified PCR product was purified with Himedia ${ }^{\circledR}$ PCR product purification kit MB512 and sent out for sequencing commercially (Eurofins genomics, Bengaluru, India). The sequences thus obtained were subjected to BLAST search in NCBI (www.ncbi.nlm.nih. gov), in order to determine the most identical sequences available on the database. Thus, a set of 19 sequences of 16s rRNA gene of eight species of Fejervarya along with a sequence of
Nannophrys marmorata as the outgroup, were selected and aligned using Muscle in MEGA 6.0 (Tamura et al. 2013). This alignment was exported in FASTA and MEGA formats. This alignment was then used to determine uncorrected pairwise genetic distances between the samples with MEGA 6. The FASTA alignment was converted to PHYLIP format in the Alignment Transformation Environment (ALTER) website (www.sing.ei.uvigo.es/ ALTER) and was subjected to a maximum likelihood (ML) analysis in RAxML GUI v. 1.3 using the general time reversible model, GTR GAMMA, (as RAxML uses only the general time reversible (GTR) model of sequence evolution) with 500 bootstrap replicates. The tree file generated was then visualized using Fig Tree v. 1.4.0.

\section{Results}

The 16s rRNA gene sequence generated during the present study from the Andaman sample of the large-bodied, mangrove-dwelling Fejervaya (NCBI reg. no: MW131314) was found to be up to $99-100 \%$ identical to 10 sequences of Fejervarya moodiei from the NCBI database (Table 1). Two of these sequences: KX055956 (Indonesia - no further locality details) and AB543602 (Cox Bazar, Bangladesh) showed a $100 \%$ similarity to the sample from Havelock in the Andaman Islands generated in this study. Intra-specific genetic divergence between these three samples (Fig. 1) was 0\%, indicating their conspecificity.

Table 1. Pairwise genetic distances (in \%) on 16s rRNA gene of Fejervarya spp. from the Andaman and Nicobar archipelago and related members. Intra-specific distances to the samples under investigation are in bold; J, Java; C, Camorta; H, Havelock Island; T, Taiwan

\begin{tabular}{|c|c|c|c|c|c|c|c|c|c|c|c|c|c|c|c|c|c|}
\hline $\begin{array}{l}\text { Fejervarya } \\
\text { Species }\end{array}$ & 1 & 2 & 3 & 4 & 5 & 6 & 7 & 8 & 9 & 10 & 11 & 12 & 13 & 14 & 15 & 16 & 17 \\
\hline \multicolumn{18}{|l|}{ limnocharis $\mathbf{J}$} \\
\hline limnocharis & 0.42 & & & & & & & & & & & & & & & & \\
\hline 'cancrivora' & 0.42 & 0.42 & & & & & & & & & & & & & & & \\
\hline limnocharis & 0.20 & 0.21 & 0.21 & & & & & & & & & & & & & & \\
\hline 'multistriata' & 0.20 & 0.21 & 0.21 & 0.00 & & & & & & & & & & & & & \\
\hline limnocharis $^{\mathrm{C}}$ & 0.20 & 0.21 & 0.21 & 0.00 & 0.00 & & & & & & & & & & & & \\
\hline sakishimensis & 2.55 & 2.56 & 2.55 & 2.34 & 2.34 & 2.34 & & & & & & & & & & & \\
\hline moodiei & 16.0 & 16.1 & 16.0 & 15.8 & 15.8 & 15.8 & 16.3 & & & & & & & & & & \\
\hline moodiei & 16.0 & 16.1 & 16.0 & 15.8 & 15.8 & 15.8 & 16.3 & 0.00 & & & & & & & & & \\
\hline moodiei $^{\mathrm{H}}$ & 16.0 & 16.1 & 16.0 & 15.8 & 15.8 & 15.8 & 16.3 & 0.00 & 0.00 & & & & & & & & \\
\hline cancrivora $^{\mathbf{T}}$ & 15.1 & 15.1 & 15.1 & 14.8 & 14.8 & 14.8 & 14.8 & 8.54 & 8.54 & 8.54 & & & & & & & \\
\hline cancrivora & 15.6 & 15.7 & 15.6 & 15.4 & 15.4 & 15.4 & 15.3 & 9.01 & 9.01 & 9.01 & 0.42 & & & & & & \\
\hline cancrivora & 15.1 & 15.1 & 15.1 & 14.8 & 14.8 & 14.8 & 14.8 & 8.54 & 8.54 & 8.54 & 0.00 & 0.42 & & & & & \\
\hline iskanderi & 11.6 & 11.6 & 11.6 & 11.3 & 11.3 & 11.3 & 11.4 & 16.0 & 16.0 & 16.0 & 12.8 & 12.8 & 12.8 & & & & \\
\hline$F$. species ${ }^{\mathbf{T}}$ & 2.76 & 2.8 & 2.77 & 2.55 & 2.55 & 2.55 & 2.12 & 16.3 & 16.3 & 16.3 & 15.0 & 15.6 & 15.0 & 12.1 & & & \\
\hline tiora & 7.62 & 7.6 & 7.62 & 7.39 & 7.39 & 7.39 & 6.93 & 15.5 & 15. & 15.5 & 12.8 & 13.3 & 12.8 & 10.6 & 7.15 & & \\
\hline orissaensis & 11.6 & 11.6 & 11.6 & 11.3 & 11.3 & 11.3 & 11.1 & 15.2 & 15.2 & 15.2 & 13.8 & 13.8 & 13.8 & 5.0 & 12.1 & 11.6 & \\
\hline $\begin{array}{l}\text { Nannophrys } \\
\text { marmorata }\end{array}$ & 14.8 & 14.8 & 14.8 & 14.5 & 14.5 & 14.5 & 14.2 & 14.4 & 14.4 & 14.4 & 12.2 & 12.7 & 12.2 & 13.8 & 15.8 & 13.5 & 14.5 \\
\hline
\end{tabular}


Therefore, the Andaman population of the $F$. cancrivora complex is hereby formally referred to Fejervarya moodiei (Taylor, 1920). Its sister species, $F$. cancrivora (Gravenhorst, 1829) showed a high genetic divergence from $F$. moodiei (8.5-9.0\%) in 16s rRNA gene. The male voucher specimen collected from Havelock, in the Andaman archipelago is briefly described below. Likewise, the 16s rRNA gene sequence generated in this study (NCBI reg. no: MW131317) from the Fejervarya sp. of Camorta was found to be up to $99 \%$ identical to 36 sequences of Fejervarya spp. which were identified as $F$. limnocharis, " $F$. multistriata" and " $F$. cancrivora" on the NCBI database (Table 1). Five of these sequences, comprising three of Fejervarya limnocharis (EU604200.1, AF215416.1 from unknown localities and a topotypical example, AB277302.1 from Java, the type locality of the species), one example of a Fejervarya identified as " $F$. cancrivora" from Taiwan (EU365385.1) and one of Fejervarya identified as " $F$. multistriata" from Husa, China (AB488884.1) formed a well-supported (99\% bootstrap) clade. Genetic divergence of the Nicobarese specimen with the members of this clade (Fig. 1) ranged from 0.0-0.2 \%, suggesting their conspecificity. Morphology of some representative specimens, calls and natural history of the newly identified population of $F$. limnocharis (Gravenhorst 1829) from the Nicobar archipelago are briefly described below.

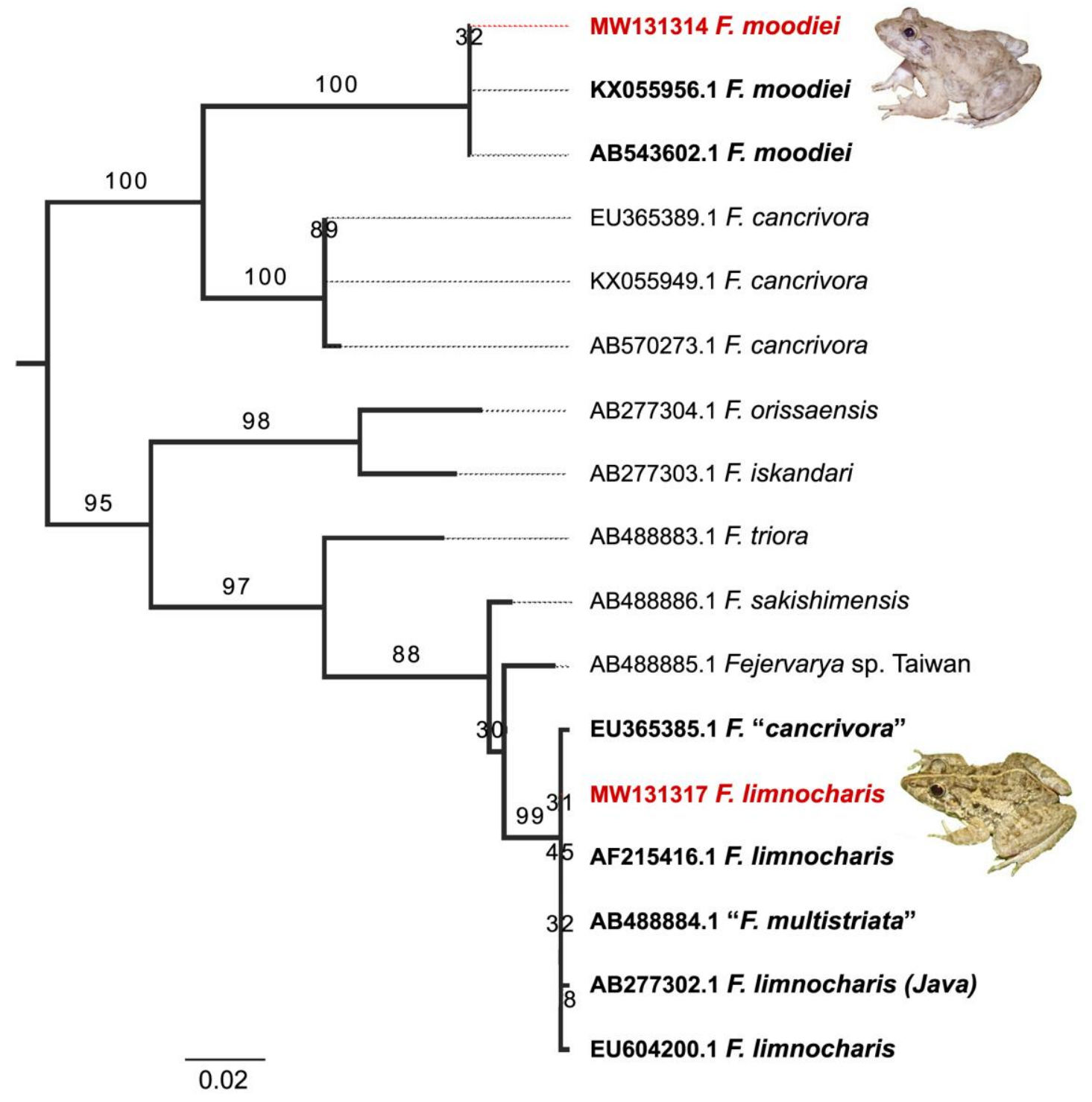

Figure 1. Maximum likelihood tree of Fejervarya spp. showing the position of $F$. moodiei from the Andaman Islands and F. limnocharis from Nicobar; outgroup taxon (Nannophrys marmorata, AY141844.2) is not shown 


\section{Plate 53}
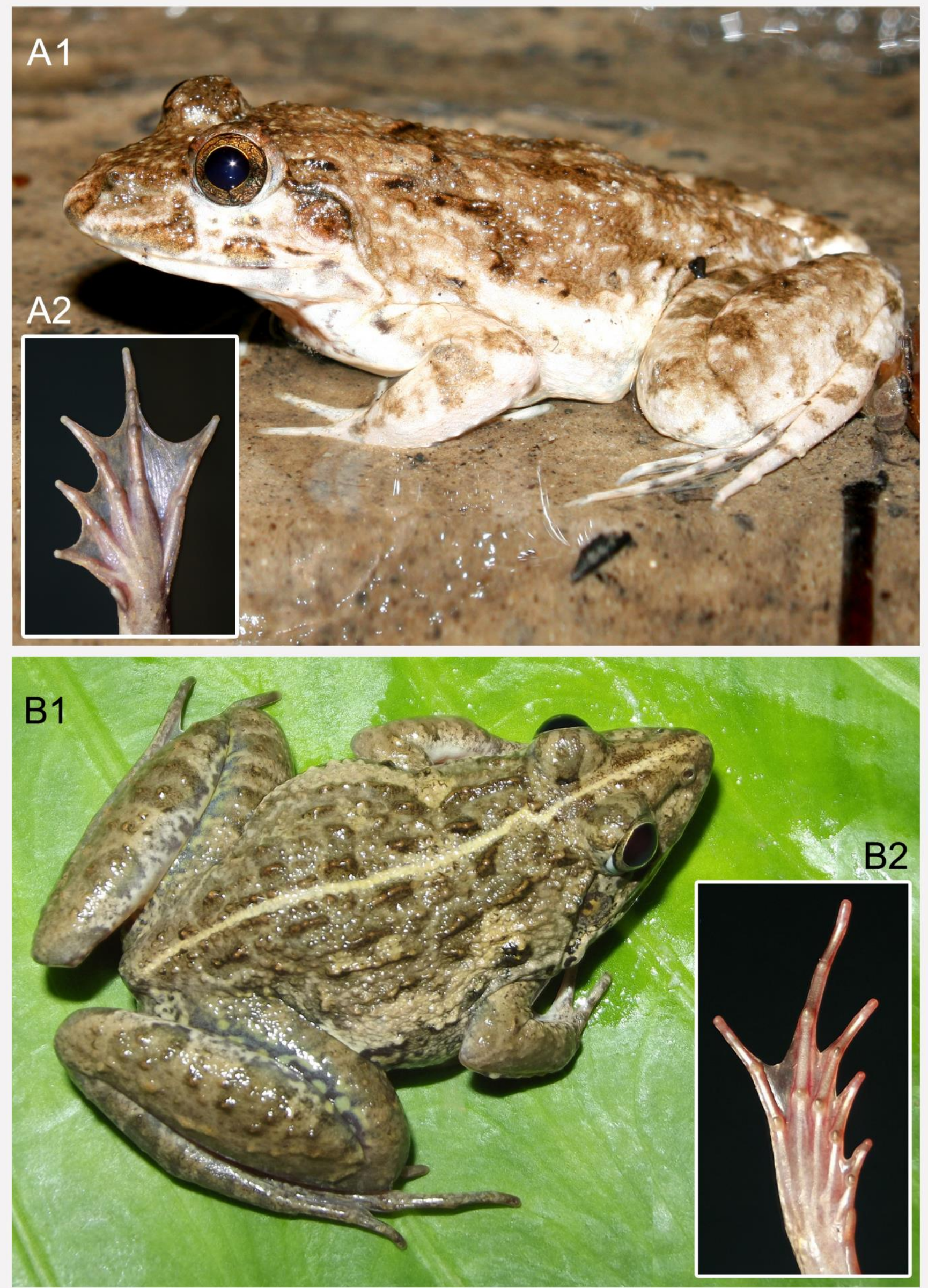

Figure 2. (A1) an adult male (not collected) and (A2) toe webbing of Fejervarya moodiei from South Andaman and (B1) an adult male (not collected) and (B2) toe webbing of Fejervarya limnocharis from Camorta, Nicobar 


\section{Plate 54}
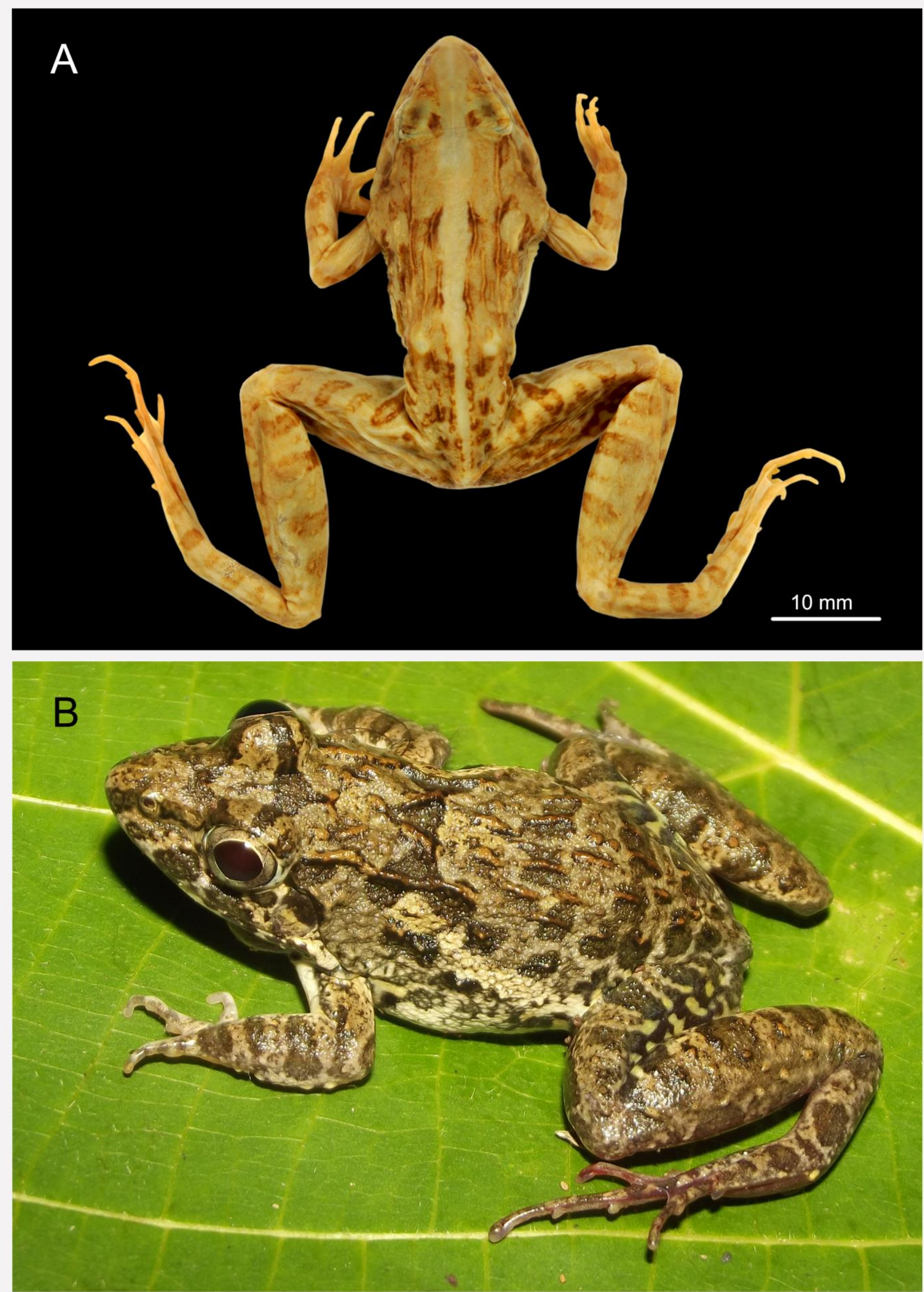

Figure 3. Fejervarya limnocharis (A) neotype, RMNH 4287 from Java, Indonesia; (B) a living individual from Car Nicobar, India (not collected) 
Fejervarya moodiei (Taylor, 1920)

(Figs. 1, 2A, 4, 5; Table 2)

Rana cancrivora - Sarkar 1990, Pillai 1991

Fejervarya cf. cancrivora - Harikrishnan et al. 2012, Chandramouli et al. 2015

Holotype. CM 3724 (formerly E.H. Taylor 1240 fide McCoy \& Richmond 1966), collected from Manila, Luzon, Philippines [not examined].

Material examined $(n=4)$. Adult male, DOSMB 05031, SVL $61.34 \mathrm{~mm}$, collected from Govind Nagar, Havelock Island, Ritche's Archipelago, the Andaman Islands, India by S.R. Chandramouli on 16 May 2017; adult male, WII HC011, SVL $62.19 \mathrm{~mm}$, collected from Long Island, the Andaman Islands, India; adult males, HC085, HC086 (SVL 48.37 and 49. 30 $\mathrm{mm}$ respectively), collected from the Andaman Islands, India; collector and date unknown.

Diagnosis with sympatric dicroglossids. Fejervarya moodiei can be identified and distinguished from other sympatric frogs by: large body size (mean SVL $55.3 \mathrm{~mm}$; range 48.37-63.48 mm); presence of multiple, interrupted, feeble longitudinal skin folds on the dorsum and along the lateral sides; an inverted V shaped fold of skin on the dorsum; a pair of dark coloured Fejervaryan lines on the venter between axilla and groin; dorsally positioned nostrils towards the snout tip; an evident supratympanic fold from the postorbital region to the shoulder; paired, dark coloured vocal sacs in males; well-developed webbing on toes extending between tips of toes III and V to the distal subarticular tubercle of toe IV; an evident inner metatarsal tubercle and the absence of an outer metatarsal tubercle.

Redescription. Based on DOSMB 05031, Adult male. Head large, broader than long (HL:HW 0.86) with a blunt, rounded snout tip, slightly projecting beyond mandible; nostrils more dorsal than lateral in position, closer to snout tip than to eyes (EN:ES 0.58); canthal region blunt and smoothly curved; eyes fairly large (ED:HL 0.26) with a rhomboidal pupil; tympanum evident, smaller than eye (TYH:ED 0.86); a thick supratympanic dermal fold from postorbital region to the shoulder evident; interorbital distance greater than internarial distance (IO:IN 1.32); upper eyelids narrower; about half as wide as interorbital space (IO:UEW 2.02); tongue broad, leaf shaped and bifid posteriorly; vomerine teeth in two short oblique rows separated from each other; upper arms short but robust (UAL:SVL 0.23); lower arm slightly longer than upper arm (UAL:LAL 0.95); palm short, a little longer than half the length of upper arm (PAL:UAL 0.61); relative lengths of fingers $3>1>4>2$; short inner and outer metacarpal tubercles present at the base of the palm; dorsal surface of first finger with a thick, fleshy nuptial pad; thighs thick and fleshy; about less than half as long as the body (FEL:SVL 0.35); shank longer than thigh (FEL:TBL 0.69); tarsus short; foot much longer than thigh (FEL:FOL 0.73); toe tips rounded; an evident dermal fringe from base of the foot to toe $\mathrm{V}$; relative toe lengths $\mathrm{IV}>\mathrm{III}>\mathrm{V}>\mathrm{II}>\mathrm{I}$; webbing between toes well-developed; webbing formula: I 0-0.5, II 0-1, III 0-1, IV 1-0 V; inner metatarsal tubercle evident and oval in shape; outer metatarsal tubercle absent.

Colouration. Overall dorsal colour sandy brown with fine sandy brown speckled markings; a dark brown inter-orbital band and a ' $\mathrm{W}$ ' shaped marking present on the back; lips with large dark brown spots; tympanum darker than the background colour; groin and posterior thighs brilliantly coloured with a dark coffee brown background and bright yellow reticulations; venter dirty white with small, indistinct grey blotches all over; vocal sacs of males dark grey to black.

Variation. Largest adult male and female recorded were of SVL 62.32 and $63.48 \mathrm{~mm}$ respectively. Adult males show a pair of welldeveloped, dark coloured gular vocal sacs and thick, fleshy nuptial pads on dorsal surface of first fingers, both of which are absent in females.

Call description. Call of Fejervarya moodiei, described here (Fig. 4) was recorded from an adult male from Carbyn's Cove, Port Blair, South Andaman on 14 June 2015 around dusk $(19: 45 \mathrm{~h})$ at an ambient air temperature of $28{ }^{\circ} \mathrm{C}$. The call was composed of three distinct notes, each of which comprised 33-35 pulses, uttered at the rate of 5 pulses/s; each pulse lasted for a mean duration of $0.01 \mathrm{~s}$, with an inter-pulse interval of $0.01-0.02 \mathrm{~s}$; length of the notes ranged from 3.5-4.5 s; mean amplitude of the call was at $-6 \mathrm{~dB}$, with a dominant frequency of $3.4 \mathrm{kHz}$.

Natural history. Fejervarya moodiei is a nocturnal species and can be found on mudflats near mangroves, especially during low tide. They were seen in small puddles of brackish water formed in depressions after the tides 
receded. The aquatic snakes Cerberus rynchops (Schneider, 1799) and Cantoria violacea Girard, 1858 were observed to be sympatric with Fejervarya moodiei and could be potential predators. Fejervarya moodiei also occurs in littoral forest and was observed on the forest floor amidst leaf litter or vegetation on a few occasions. Information on breeding biology and larval morphology are not known. However, metamorphs measuring about $15 \mathrm{~mm}$ SVL were recorded from coastal forest floor in February 2015 suggesting that this species might breed during the northeast monsoon, which lasts from late September to early December.
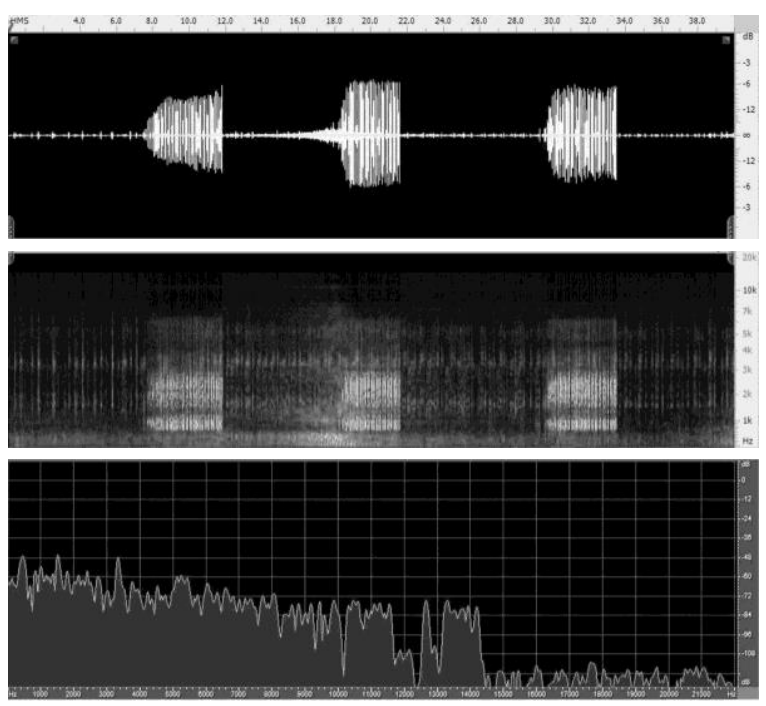

Figure 4. Call characteristics: oscillogram (above), spectrogram (middle) and power spectrum (below) of Fejervarya moodiei recorded from South Andaman

Distribution. Fejervarya moodiei is a widely distributed species occurring in several continental and insular regions of South and Southeast Asia namely, Orissa in Peninsular India at the western extremity through Thailand, southern China to the Philippines in the Far East. Within the Andaman archipelago (Fig. 5), $F$. moodiei was recorded from North, Middle, South and Little Andaman Islands, Paget Island, North Reef Island, Interview Island, Long Island, Guitar Island, Kyd Island; Tarmugli and Redskin Islands in the Labyrinth Archipelago situated in the southwestern part of the Great Andaman chain and Havelock, Neil, John Lawrance and Henry Lawrance Islands in Ritchie's archipelago located to the east of the major island chain. It does not occur in the Nicobar Archipelago. The status of the frogs reported as Fejervarya cf. cancrivora from the
Nicobar archipelago (see Frost 2020) are dealt with below in detail.

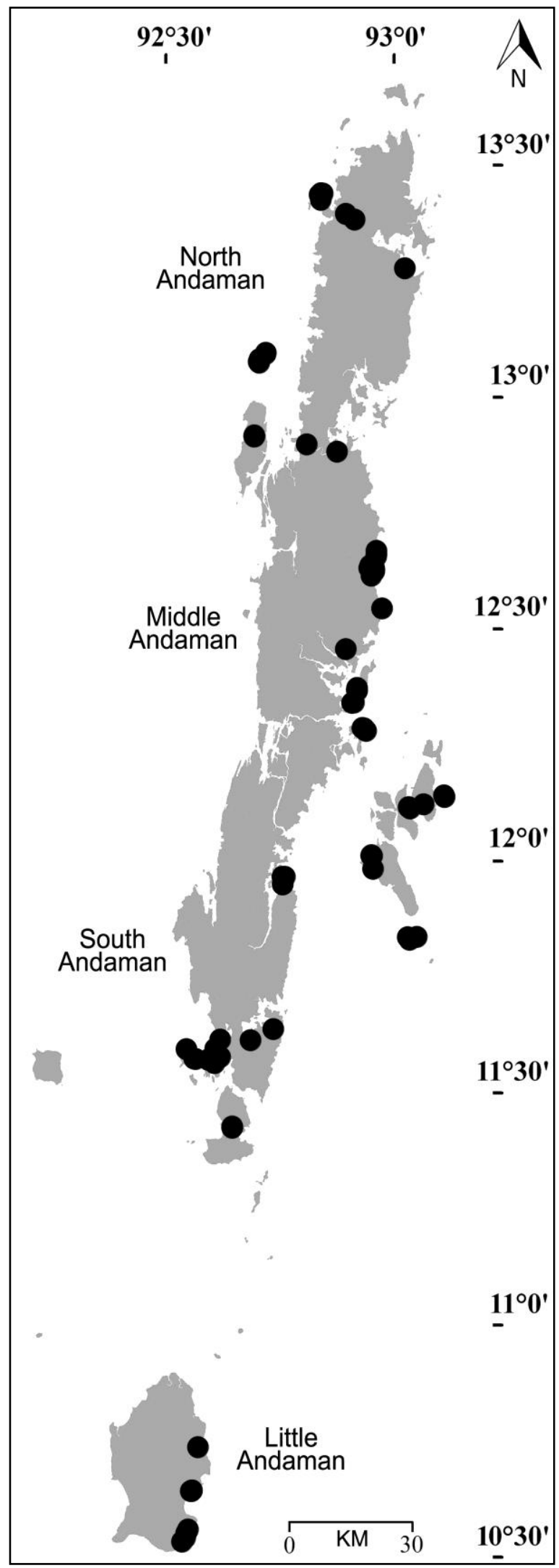

Figure 5. Distribution of Fejervarya moodiei in the Andaman Archipelago 
Fejervarya limnocharis (Gravenhorst, 1829) (Figs. 1, 2B, 3, 6-8; Table 2)

Neotype. Subadult female, RMNH 4287, SVL 44.4, collected from Java, Indonesia (designated by Dubois \& Ohler 2000).

Material examined $(\boldsymbol{n}=5)$. Adult males, DOSMB 05081, DOSMB 05082 and ZSI/ANRC/T/12327 (SVL 44.98, 46.78, and $50.46 \mathrm{~mm}$ respectively, collected from a human settlement on Camorta Island near the harbor $\left(8.04^{\circ} \mathrm{N}, 93.54^{\circ} \mathrm{E}\right.$, alt. $28 \mathrm{~m}$ a.s.1.), the Nicobar Islands, India, by S.R. Chandramouli on 23 June 2017; Adult females, WII HS52 and WII HS53 (SVL 57.04 and $42.75 \mathrm{~mm}$ respectively), collected from Car Nicobar, the Nicobar Islands, India; collector and date unknown.

Diagnosis with sympatric dicroglossid. Fejervarya limnocharis can be diagnosed and distinguished from the other sympatric dicroglossid, Minervarya nicobariensis in the Nicobar archipelago by having a pointed snout tip projecting beyond mandible ( $v s$ blunt and rounded), striking dark colouration with a bright, creamy yellow spotted pattern on posterior surface of the thighs ( $v s$ absent); pointed terminals of digit tips ( $v s$ blunt and rounded). Fejervarya limnocharis co-occurs with $M$. nicobariensis in islands of the central group of the Nicobars (see below).

Description of Nicobar specimens. Based on DOSMB 05081, DOSMB 05082 and ZSI/ANRC/T/ 12327 ( $n=3)$. Large bodied frogs (mean SVL $47.4 \mathrm{~mm} \pm 2.8$ ) with a moderately slender habitus; head large (HL:SVL 0.3), slightly longer than broad (mean HL:HW 1.13) with an acutely pointed snout tip when viewed dorsally, which projects beyond the mandible; eyes large (mean ED:HL 0.3), internarial (mean $3.2 \mathrm{~mm}$ ) wider than interorbital space (mean 2.2 $\mathrm{mm}$ ); tympanum exposed, fairly large, more than half the size of the eye (mean TYH:ED 0.6 ); an evident supratympanic fold extending from eye to shoulder. Upper arm short (mean UAL:SVL 0.2); lower arms as long as the upper arm (mean UAL:LAL 1); palm a little longer than lower arm (man $9.89 \mathrm{~mm}$ ) with long fingers bearing pointed tips.; thighs robust and long, about half the length of the body (mean FEL:SVL 0.5); tibia longer than thigh (mean TBL:SVL 0.6); feet a little longer than thigh (mean FEL: FOL 0.9); toes with pointed tips lacking discs; moderate degree of webbing; webbing formula: I $0.5-1$, II $0.5-1.5$, III 0.5-1.5, IV 1.5-1, V.

Colouration. Dull brown to grey dorsally with dark spots and a ' $\mathrm{W}$ ' shaped marking on the back; an inverted triangular marking between the eyes; posterior surface of the thighs dark brown with creamy yellow spots; venter uniform white in females; males with a pair of dark black gular vocal sacs.

Call description. Calls of Fejervarya limnocharis described here (Fig. 6) were recorded from an adult male on Camorta Island in the central group of the Nicobar archipelago. The call consists of a multi-pulsed note $(10-25$ pulses / note), which lasts for a duration of $15 \mathrm{~s}$, with each pulse lasting for a mean duration of $0.14 \pm 0.02 \mathrm{~s}$, uttered at a rate of 4.5 pulses/s; dominant frequency of the call was at $3 \mathrm{kHz}$; inter pulse-interval ranges from $0.07-0.13 \mathrm{~s}$.

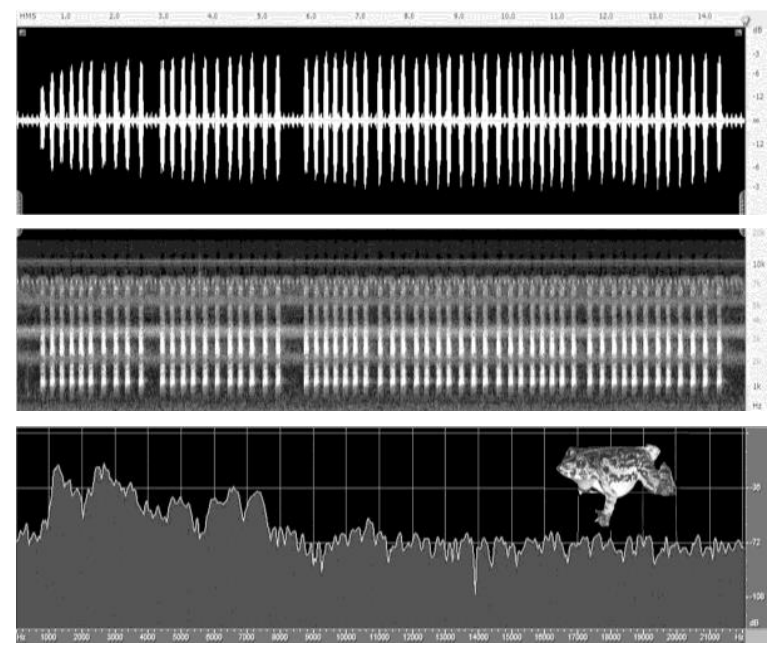

Figure 6. Call characteristics: oscillogram (above), spectrogram (middle) and power spectrum (below) of Fejervarya limnocharis recorded from Camorta.

Larval description. Larvae of Fejervarya limnocharis were observed in tanks and roadside puddles even close to human habitation. Tadpoles of stage 34 are described herein (Fig. 7). Overall size small, measuring $31.0 \mathrm{~mm}$ total length, with an $11 \mathrm{~mm}$ long head-body and 20 $\mathrm{mm}$ long tail; head-body more than twice as long as broad (HBL:HBW 2.4) and nearly as deep as broad (HBW:HBD 1.07); eyes small (ED $1.2 \mathrm{~mm}$ ), shorter than the snout (ED:ES 0.66 ); inter-orbital space wider than internarial distance (IO:IN 1.42); caudal fins broad (CFH 3 $\mathrm{mm}$ ) with a well-developed caudal musculature; oral disc broad (ODW 1mm), labial tooth row formula 3/2//1/1; upper and lower jaw-sheaths well-developed with serrated inner edges; spiracle sinistral; vent tube dextral. 
Larval colouration. Dorsum uniform brownish in colour with a pale white, translucent venter, through which, the highly coiled gut is visible from below.

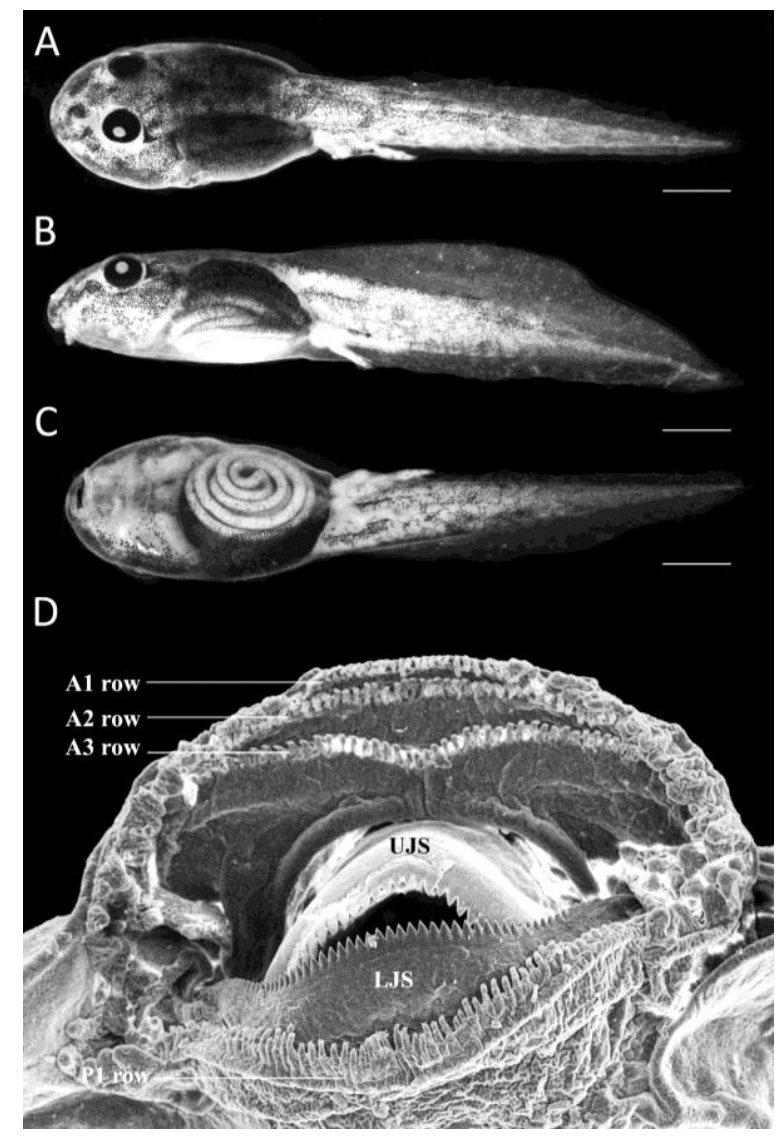

Figure 7. The tadpole of $F$. limnocharis from Camorta, Nicobar (A) dorsal, (B) lateral, (C) ventral view of the body, and (D) mouthparts; Scale: $2 \mathrm{~mm}$
Natural history. A common species occurring mostly in open habitats such as grasslands and roadside vegetation. Not recorded from pristine evergreen forests. Resistant to anthropogenic habitat disturbance. Breeding commences with the onset of the southwest monsoon in late May/June untill September. Breeding pairs often sighted in rainwater puddles on roadsides. Tadpoles were observed in potholes on roads filled with rain water.

Distribution. Recorded in islands of the northern and central groups of the Nicobar archipelago (Fig. 8): Car Nicobar, Camorta, Nancowry, Trinkat and Teressa Islands. Not found in Great and Little Nicobar, the southern group of Nicobar Islands and Katchall Island in the central group of the Nicobars. Elsewhere, widespread in parts of Sundaland including Sumatra, Borneo and Java. Also occurs in parts of Indochina, Taiwan and China.

\section{Discussion}

Fejervarya cancrivora, once considered to be widespread throughout south-east Asia (e.g. Boulenger 1920, Dutta 1997) was subsequently found to comprise cryptic lineages based on evidences from morphological, genetic, allozyme data and crossing over experiments (Islam et al. 2008, Kurniawan et al. 2010, Kurniawan et al. 2011), which now are assigned to the taxa Fejervarya cancrivora (Gravenhorst, 1829) and Fejervarya moodiei (Taylor, 1920).

Table 2. Measurements of $F$. moodiei from the Andaman Islands and F. limnocharis from Nicobars (in mm)

\begin{tabular}{lccc|ccc}
\hline \multirow{2}{*}{ Character } & \multicolumn{2}{c|}{ Fejervarya moodiei } & \multicolumn{2}{c}{ Fejervarya limnocharis } \\
\cline { 2 - 7 } & Range & Mean & \pm SD & Range & Mean & \pm SD \\
\hline SVL & $48.37-62.19$ & 55.30 & 7.48 & $46.8-50.5$ & 47.4 & 2.79 \\
Head length & $18.32-22.07$ & 19.58 & 1.69 & $14.9-17.0$ & 16.1 & 1.08 \\
Head width & $18.45-22.24$ & 20.41 & 2.10 & $13.3-14.7$ & 14.2 & 0.78 \\
Head depth & $7.06-10.34$ & 8.36 & 1.40 & $6.1-6.9$ & 6.6 & 0.43 \\
Eye diameter & $5.04-5.89$ & 5.41 & 0.38 & $4.0-5.1$ & 4.7 & 0.61 \\
Eye-nostril length & $4.51-5.66$ & 5.13 & 0.57 & $3.9-4.6$ & 4.3 & 0.4 \\
Eye-snout length & $8.53-9.84$ & 8.15 & 2.97 & $7.2-8.2$ & 7.7 & 0.48 \\
Tympanum diameter & $3.08-4.33$ & 3.91 & 0.76 & $2.5-3.1$ & 2.7 & 0.31 \\
Upper eyelid width & $2.06-3.95$ & 3.25 & 0.84 & $3.0-3.4$ & 3.3 & 0.22 \\
Inter orbital distance & $3.24-4.17$ & 3.75 & 0.38 & $1.5-2.8$ & 2.2 & 0.68 \\
Internarial distance & $3.1-4.1$ & 3.50 & 0.50 & $2.5-3.7$ & 3.2 & 0.58 \\
Upper arm length & $11.3-15.1$ & 13.00 & 1.93 & $8.3-10.8$ & 9.5 & 1.28 \\
Lower arm length & $9.35-14.83$ & 12.06 & 2.37 & $8.5-10.4$ & 9.4 & 0.96 \\
Palm length & $8.54-12.92$ & 9.95 & 2.00 & $9.4-10.3$ & 9.9 & 0.44 \\
Femur length & $19.16-26.74$ & 21.72 & 3.49 & $20.8-24.3$ & 22.2 & 1.85 \\
Tibia length & $22.05-31.32$ & 26.74 & 4.56 & $24.1-27.0$ & 25.9 & 1.66 \\
Tarsus length & $13.9-16.14$ & 14.86 & 1.04 & $11.6-13.2$ & 12.3 & 0.84 \\
Foot length & $22.05-31.94$ & 26.43 & 5.04 & $23.3-26.1$ & 24.7 & 1.4 \\
\hline
\end{tabular}




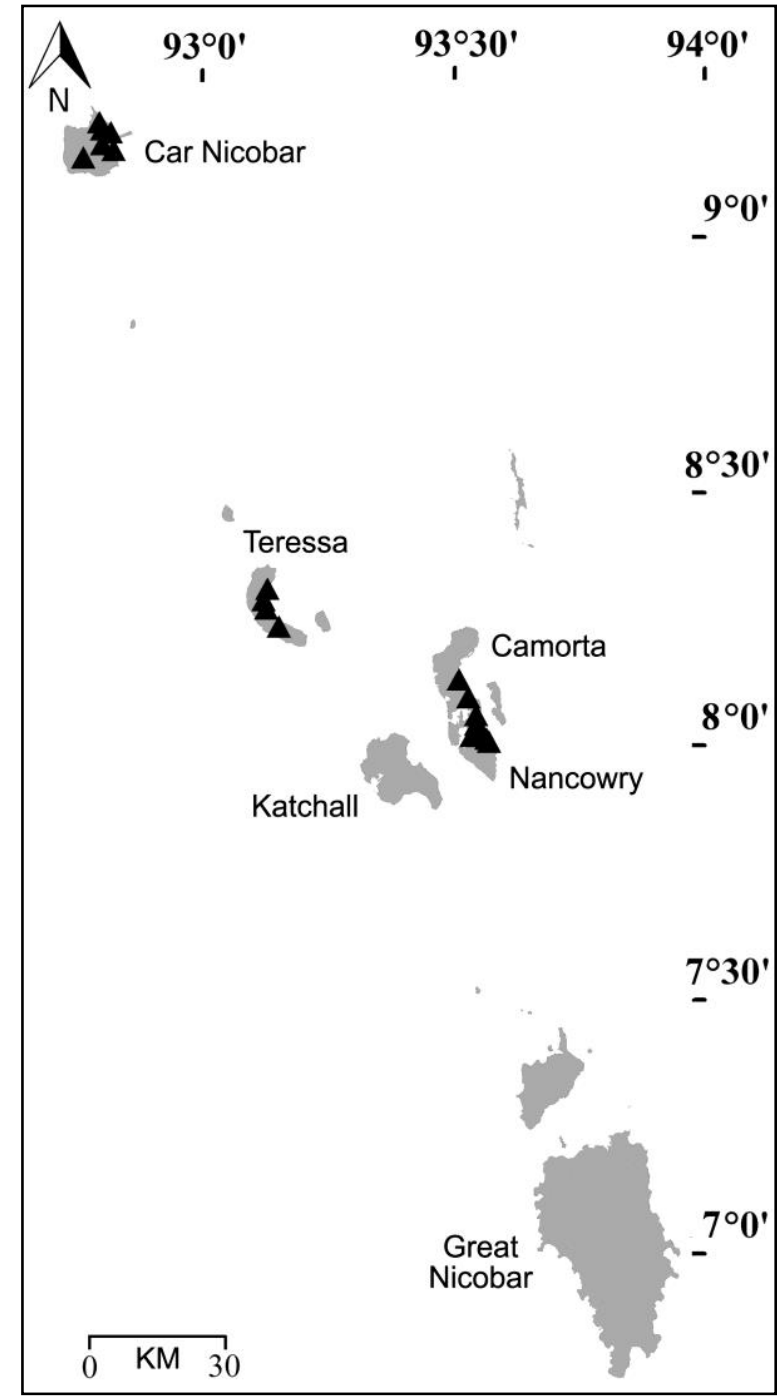

Figure 8. Distribution of Fejervarya limnocharis in the Nicobar Archipelago

The nomen Fejervarya raja (Smith, 1920) is currently considered to be a synonym of $F$. cancrivora (Gravenhorst, 1829) (see Frost 2020). The occurrence of a mangrove-dwelling frog in the Andaman Archipelago was first reported by Sarkar (1990) as Rana cancrivora from Wright Myo, South Andaman. Overlooking this record, Pillai (1991) reported 'Rana cancrivora' from Carbyn's Cove, South Andaman and Krishnanagar on Havelock. Subsequent studies that recorded this mangrove dwelling frog species reported it as Fejervarya cf. cancrivora (e.g. Harikrishnan et al. 2014, Chandramouli et al. 2015, Rangasamy et al. 2018). Frost (2020) remarked that the identity of the Andaman population of $F$. cf. cancrivora still remains unresolved. Yodthang et al. (2019) assessed the taxonomic identities of the mangrove frogs of mainland Southeast Asia, but just made speculations for the island species, as they did not have access to specimens from the Andaman Islands. Herein, the taxonomic status of the Andamanese population of the mangrove dwelling Fejervarya has been determined using molecular methods and it was confirmed to be $F$. moodiei, a species with a more Indochinese than Indo-Malayan distribution within the $F$. cancrivora complex.

The dicroglossid frog $F$. limnocharis is reported here for the first time from the Nicobar archipelago. This population, however, has been sampled in earlier studies from this region. Vijayakumar (2005: 43) reported and illustrated this species as a potentially new Fejervarya sp. and recorded it from Camorta, Teressa, Trinkat and $\mathrm{Car}$ Nicobar. However, no subsequent attempt has been made to resolve its identity until now. Harikrishnan \& Vasudevan (2018) reported 'Fejervarya cancrivora' from Car Nicobar based on their material WII HS52 and 53, which, in fact, is a case of misidentification. Examination of their material during the present study revealed that they actually represent $F$. limnocharis. Another dicroglossid, Minervarya nicobariensis co-occurs on some of the islands in the central group of Nicobars (see Chandramouli \& Prasad 2020).

The nomen $F$. multistriata was revalidated from the synonymy of $F$. limnocharis by Dubois \& Ohler (2000) by virtue of a neotype designation. However, whether or not $F$. multistriata is a distinct species from $F$. limnocharis has been a subject of debate for a long time (Dubois \& Ohler 2000, Huang \& Tu 2018, Frost 2020). Analysis of molecular data from Chinese specimens, identified as ' $F$. multistriata' and the Javan topotype specimens of $F$. limnocharis shows a very shallow genetic divergence of $0.2 \%$. As the sequenced sample identified as 'Fejervarya multistriata' originates from Husa, which is $\sim 1600$ airline km west of Hong Kong, the type locality of $F$. multistriata, we refrain from commenting on its taxonomic status and urge inclusion of topotypic $F$. multistriata in future studies. The specimen from the Nicobars sequenced in our study shows a divergence of $0.0-0.2 \%$ at the $16 \mathrm{~S}$ rRNA gene from topotypical $F$. limnocharis and samples identified as ' $F$. multistriata', strongly suggesting that these populations are conspecific. This is also complemented by their morphological similarities, which support the present conclusion that $F$. limnocharis (Gravenhorst, 1829) is a widespread species, occurring throughout most of tropical Asia. As a 
result, the distribution of Fejervarya limnocharis is expanded considerably, ranging from the Nicobar Islands in the western extremity, through China across the Isthmus of Kra all the way to East Malaysia and Java, making it one of the most widely distributed amphibian species of south-east Asia.

\section{Acknowledgement}

We thank the Department of Environment and forests, Andaman and Nicobar Islands for support and permission (Permit Nos: CWLW/WL/134/(J)/Folder/417 and CWLW/WL/134 (L)/ 60) to conduct the fieldwork; faculty of the Department of Ecology and Environmental sciences and the Department of Biotechnology at the main campus for the support extended. The faculty of the Department of Ocean studies and marine biology of Pondicherry University campus at Port Blair for hospitality are acknowledged for their hospitality. This study was partly supported by the Mohamed bin Zayed Species Conservation Fund (Grant No: 160514249). We also thank Enrique La Marca (University of the Andes, Venezuela), Nikolay A. Poyarkov, Jr. (Lomonosov Moscow State University, Russia), and Philip Bowles (IUCN) for valuable comments and reviewing the manuscript. Fianally Mark Oliver Roedel and Frank Tillack (ZMB, Berlin), Allen Resetar (FMNH, Chicago) and Esther Dondorp (RMNH, Leiden) are thanked for sending the photographs of the specimens of $F$. multistrata and $F$. limnocharis respectively. Finally we thank C. Sivaperuman (ZSI, Andaman \& Nicobar Regional Center) for cataloging the specimens in their collection.

\section{Literature cited}

Boulenger, G.A. (1920). A monograph of the South Asian, Papuan, Melanesian and Australian frogs of the genus Rana. Records of the Indian Museum, 20: 1-226.

Chandramouli, S.R. and A. Kalaimani (2014). Description of the larvae of Günther's toad Duttaphrynus hololius (Günther, 1876)(Anura: Bufonidae) with notes on development and oral ultra-structure. Alytes, 31: 3-12.

Chandramouli, S.R. and K.V.D. Prasad (2020). Redescription of Minervarya nicobariensis (Stolizka, 1870) (Amphibia: Dicroglossidae) with a neotype designation. Taprobanica, 9 (2): 205-209.

Chandramouli, S.R., T. Khan, R. Yathiraj, N. Deshpande, S. Yadav et al. (2015). Diversity of amphibians in Wandoor, South Andaman,
Andaman and Nicobar Islands, India. Alytes, 32: 47-54.

Das, I. (1999). Biogeography of the amphibians and reptiles of the Andaman and Nicobar Islands, India. In: Ota, H. (ed). Tropical Island herpetofauna. Origin, current diversity and current status. Elsevier: 43-77.

Dubois, A., A. Ohler, and S.D. Biju (2001). A new genus and species of Ranidae (Amphibia, Anura) from Southwestern India. Alytes, 19: 53-79.

Dubois, A. and A. Ohler (2000). Systematics of Fejervarya limnocharis (Gravenhorst, 1829) (Amphibia, Anura, Ranidae) and related species I. Nomenclatural status and type specimens of the nominal species Rana limnocharis Gravenhorst, 1829. Alytes, 18: 15-50.

Dutta, S.K. (1997). The Amphibians of India and Sri Lanka; Checklist and Bibliography. Odyssey Publishing House, Orissa: 342pp.

Frost, D.R. (2020). Amphibian Species of the World: an Online Reference. Version 6.0. Electronic Database accessible. American Museum of Natural History, New York <http://research.amnh.org/herpetology/amphib ia/index.html> Accessed on 4 October 2020.

Gosner, K.L. (1960). A simplified table for staging anuran embryos and larvae with notes on identification. Herpetologica, 16: 183-190.

Harikrishnan, S., S.R. Chandramouli, and K. Vasudevam (2012). Survey of herpetofauna on Long Island, Andaman and Nicobar Islands, India. Herpetological Bulletin, 119: 19-28.

Harikrishnan, S., K.Vasudevan, A. Das, B.C. Choudhury, S.K. Dutta et al. (2014). Macroecology of terrestrial herpetofauna in Andaman \& Nicobar Archipelago. WII Technical Report, Dehardun: 49pp.

Harikrishnan, S. and K. Vasudevan (2018). Amphibians of the Andaman \& Nicobar Islands: distribution, natural history, and notes on taxonomy. Alytes, 36: 238-265.

Huang, Z.H. and F.Y. Tu (2018). Mitogenome of Fejervarya multistriata: a novel gene arrangement and its evolutionary implications. Genetics \& Molecular Research, 15: 1-9.

Islam, M.M., N. Kurose, M.R. Khan, T. Nishizawa, M. Kuramoto et al. (2008). Genetic divergence and reproductive isolation in the genus Fejervarya (Amphibia: Anura) from Bangladesh inferred from morphological observations, crossing experiments, and molecular analyses. Zoological Science, 25 (11): 1084-1105.

Kocher, T.D., W.K. Thomas, A. Meyer, S.V. Edwards, S. Pääbo et al. (1989). Dynamics of 
mitochondrial DNA evolution in animals: amplification and sequencing with conserved primers. Proceedings of the National Academy of Sciences of the United States of America, 86: 6192-6200.

Köhler, J., J.M. Jansen, A. Rodríguez, P. J.R. Kok, L.F. Toledo et al. (2017). The use of bioacoustics in anuran taxonomy: theory, terminology, methods and recommendations for best practice. Zootaxa, 4251: 1-124.

Köhler, G., L. Mogk, K.P.P. Khaing, and N.L. Than (2019). The genera Fejervarya and Minervarya in Myanmar: description of a new species, new country records, and taxonomic notes (Amphibia, Anura, Dicroglossidae). Vertebrate Zoology, 69: 183-226.

Kuramoto, M., S.H. Joshy, A. Kurabayashi, and M. Sumida (2007). The genus Fejervarya (Anura: Ranidae) in Central Western Ghats, India, with the description of four new cryptic species. Current Herpetology, 26 (2): 81-105.

Kurniawan, N., M.M. Islam, T.H. Djong, T. Igawa, M.B. Daicus et al. (2010). Genetic divergence and evolutionary Relationship in Fejervarya cancrivora from Indonesia and other Asian countries inferred from allozyme and MtDNA sequence analyses. Zoological Science, 27 (3): 222-233.

Kurniawan, N., T.H. Djong, M.M. Islam, T. Nishizawa, D.M. Belabut et al. (2011). Taxonomic status of three types of Fejervarya cancrivora from Indonesia and other Asian countries based on morphological observations and crossing experiments. Zoological Science, 28: $12-24$.

McDiarmid, R.W. and R. Altig (1999). Tadpoles: the biology of anuran larvae. University of Chicago Press, Chicago: 476pp.

McCoy, C.J. and N. D. Richmond (1966). Herpetological type specimens in Carnegie Museum. Annals of the Carnegie Museum, 38: 233-264.
Sanchez, E., S.D. Biju, M. M. Islam, M. Hassan, A. Ohler (2018). Phylogeny and classification of fejervaryan frogs (Anura: Dicroglossidae). Salamandra, 54: 109-116.

Savage, J.M., and W.R. Heyer (1997). Digital webbing formulae for anurans: a refinement. Herpetological Review, 28: 131.

Sarkar, A.K. (1990). Taxonomic and ecological studies on the amphibians of Andaman and Nicobar Islands, India. Records of the Zoological Survey of India, 86: 103-117.

Stoliczka, F. (1870). Observations on some Indian and Malayan amphibia and reptilia. The journal of the Asiatic Society of Bengal, 39 (3): 134-228.

Pillai, R.S. (1991). Contribution to the amphibian fauna of Andaman and Nicobar with a new record of the mangrove frog Rana cancrivora. Records of the Zoological Survey of India, 88: 41-44.

Rangasamy, V., C. Sivaperuman, G. Gokulakrishnan, and P. Parthipan (2018). Herpetofauna of Andaman and Nicobar Islands. In: Sivaperuman C. and $\mathrm{K}$. Venkataraman (eds.). Indian Hotspots: 37-56.

Tamura, K., G. Stecher, D. Peterson, A. Filipski, and S. Kumar (2013). MEGA6: Molecular Evolutionary Genetics Analysis Version 6.0. Molecular Biology \& Evolution, 30: 27252729.

Vijayakumar, S.P. (2005). Status and distribution of Amphibians and Reptiles of the Nicobar Islands, India. Final Report. Rufford Foundation/Madras Crocodile Bank/Wildlife Institute of India: 48pp.

Yodthong, S., B.L. Stuart, and A. Awophol (2019). Species delimitation of crab-eating frogs (Fejervarya cancrivora complex) clarifies taxonomy and geographic distributions in mainland Southeast Asia. Zoo Keys, 883: 119153. 
- blank page -

TAPROBANICA VOL. 09: NO. 02 